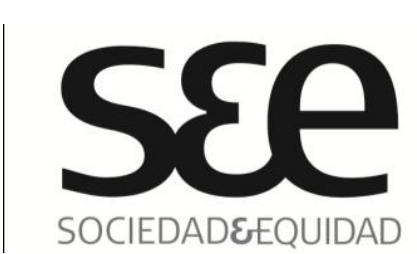

\title{
Representaciones sociales de pobreza y sus correlatos en política social
}

\author{
Nombre: $\quad$ María de los Angeles Villaseca \\ Ingrid Padópulos \\ Universidad: Fundación para la Superación de la Pobreza \\ Ciudad: $\quad$ Santiago \\ País: $\quad$ Chile \\ Correo: mvillaseca@indh.cl \\ ingrid.padopulos@superacionpobreza.cl
}

\section{RESUMEN}

El perfil de la pobreza ha cambiado en las últimas décadas, transformándose desde uno de carencias básicas, a una situación de exclusión social y precaria participación ciudadana. Esto impulsa a una reflexión sobre las imágenes sociales de la pobreza y a la necesidad de remirar el fenómeno, adoptando perspectivas vinculadas a pobreza relativa y subjetiva por sobre las representaciones de pobreza absoluta. Con todo, estos nuevos perfiles de pobreza coexisten con las pobreza por atraso o estructural, evidenciando una fuerte heterogeneidad que demanda ser reconocida en la acción pública orientada a su superación. El desarrollo de la investigación cualitativa permite adentrarse en la comprensión de esta heterogeneidad y en los impactos que tienen la prevalencia de imaginarios de pobreza dura en la relación que genera el Estado con las personas en pobreza. Este estudio presenta las dimensiones subjetivas de dicha relación y de su mutación desde una pobreza de ingresos a pobreza cívica, caracterizada por mayores demandas de integración simbólica y actoría social. Se presentan las valoraciones del vínculo sostenido con el Estado y algunas paradojas de la política social que requieren ser abordadas en la discusión pública sobre las estrategias de superación de pobreza.

\section{PALABRAS CLAVES}

Imaginario Social; Pobreza Equipada; Pobreza Esforzada; Pobreza Cívica.

\section{ABSTRACT}

The profile of poverty has changed in the recent decades, transforming from one based on shortcomings to a situation of social exclusion and precarious citizen participation. This drives a reflection on social images of poverty and the need to take a new look at poverty: from representations of absolute poverty to views of relative and subjective poverty. However, these new poverty profiles co-exist with the backwardness poverty or structural poverty, showing a strong heterogeneity that demands to be recognized in public action oriented towards improvement. The development of qualitative research enables delving in the understanding of 


\section{s\&e \\ SOCIEDADEEQUIDAD}

this heterogeneity and the impacts on the prevalence of harsh poverty imaginaries in the relationship that the States generates with people in poverty. This study presents the subjective dimensions of this relationship and its mutation from poverty of income to civic poverty, characterized by increasing demands of symbolic integration and social protagonism. It presents the ratings of the bond with the State and some paradoxes of social policy that need to be addressed in public discussion on strategies for overcoming poverty.

\section{KEYWORDS}

Social Imaginary; Equipped Poverty; Strained Poverty; Civic Poverty. 


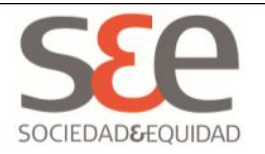

\section{Introducción}

El fenómeno de la pobreza ha sufrido importantes variaciones en la última década, por lo que han aumentado los estudios que intentan redefinir este fenómeno social y ajustar los instrumentos con los que los Estados intentan medirla. Las distinciones de pobreza absoluta, relativa y subjetiva vuelven a tomar relevancia en la discusión pública, ya no solo como un problema de estrategias de medición, sino también como una aproximación a la complejidad del fenómeno. Los conceptos de nueva pobreza y de exclusión social con los que se intenta dar cuenta de las situaciones de escasa participación socioeconómica de determinados grupos en las sociedades desarrolladas (Monreal, 1996; Kasarda, citados en Espinoza, 2009), y de vulnerabilidad o acumulación de desventajas, que vivencian determinados grupos sociales (Moser, 1998; Katzman y Filgueira, 1999), posicionan de una manera diferente el fenómeno de la pobreza, poniendo énfasis en los factores relacionales y distributivos, por sobre la dimensión de ingresos. Por ello los sistemas de medición de la pobreza y los instrumentos de focalización están en permanente discusión, más aun cuando crece la conciencia de que estas aproximaciones van delimitando una concepción de pobreza y prefijando la acción que el Estado desarrolla en función de su erradicación.

En esa misma línea, el avance de las investigaciones cualitativas han permitido sustentar modelos comprensivos del fenómeno construidos desde el rescate de la subjetividad de los propios afectados por el fenómeno de la pobreza, integrando como evidencia los autoconceptos y los imaginarios sociales que se construyen y van codeterminando el sistema de relaciones sociales entre los individuos que conforman una misma sociedad, y entre éstos con el Estado. En ese rescate de subjetividades y comprensión ontológica en que se enmarca el siguiente análisis. Sustentado en la base de datos generada en el estudio Voces de la Pobreza, desarrollado por la Fundación Superación Pobreza (2010), se profundiza en la definición de pobreza, su heterogeneidad y la naturaleza de los vínculos que la población que participa del circuito de la pobreza establece con el Estado.

Para ello, se ha utilizado la información recogida de 55 entrevistas grupales desarrolladas con personas no organizadas, que han vivenciado o están vivenciando situaciones de pobreza. Las entrevistas fueron implementadas en 54 comunas distribuidas en las 15 regiones del país, y en las que se trabajaron los tópicos de la definición / delimitación de la pobreza, las causas, las soluciones y las expectativas que se visualizan para superar dicha situación. Adicionalmente se desarrollaron 34 entrevistas en profundidad a dirigentes sociales, en las que se trataron iguales tópicos, y que también fueron considerados en este análisis de las imágenes de pobreza y la relación de la población en pobreza con el Estado.

La base de datos cualitativa generada se ha estudiado a través de análisis de contenido y aplicando teoría fundamentada, con apoyo del software QSR NVIVO 8.0, y algunas de las afirmaciones y hallazgos han sido contrastados con la información afín de la serie Casen 20002009. 


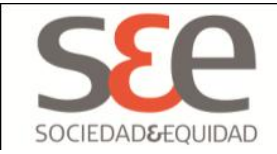

En este artículo se abordará, en una primera parte, las percepciones que estructuran los perfiles de pobreza, y que dan cuenta de su heterogeneidad, así como los desencuentros que se producen entre el autoconcepto de la población en pobreza, respecto al imaginario social predominante y que está fuertemente presente en los operadores locales de la política social. La segunda parte, trabajará sobre las percepciones de relaciones sujetos en pobreza / Estado, sus valoraciones y demandas, para finalmente establecer algunas rutas críticas para las políticas de superación de pobreza que se derivan de lo expresado en esas voces.

\section{Dinámica socioeconómica y heterogeneidad de la pobreza}

Los acelerados procesos de cambio que han afectado a la sociedad han tenido un fuerte impacto en la vivencia de la pobreza: las fluctuaciones de ingresos mensuales de los hogares a partir de los ciclos económicos y estacionales, que dan un acceso temporal y una inserción precaria al mercado del trabajo, y el establecimiento de una sociedad de consumo han transformado también las percepciones de la calidad de vida que parece deseable y el grado de desigualdad que es tolerable al interior de las sociedades (Henríquez et al., 2006: 122).

Cuadro 1. Estabilidad del empleo en asalariados, por decil de ingreso autónomo

\begin{tabular}{|l|l|l|l|l|l|l|l|l|l|l|l|}
\cline { 2 - 9 } \multicolumn{1}{c|}{} & \multicolumn{9}{|l|}{ Decil Autonomo Na cional } \\
\hline $\begin{array}{l}\text { Permanencia en el } \\
\text { empleo }\end{array}$ & I & II & III & IV & V & VI & VII & VIII & IX & X & $\begin{array}{l}\text { Tota } \\
\text { I }\end{array}$ \\
\hline Meno5 de año & 49,0 & 40,6 & 39,8 & 35,0 & 33,7 & 31,1 & 27,8 & 23,1 & 20,9 & 15,2 & 29,5 \\
\hline 1 a 3 años & 19,5 & 25,5 & 25,7 & 27,8 & 28,9 & 29,2 & 28,9 & 27,2 & 30,4 & 30,5 & 28,1 \\
\hline más de 3 año5 & 31,5 & 34,0 & 34,6 & 37,1 & 37,4 & 39,7 & 43,3 & 49,7 & 48,7 & 54,3 & 42,4 \\
\hline Total & 100 & 100 & 100 & 100 & 100 & 100 & 100 & 100 & 100 & 100 & 100 \\
\hline
\end{tabular}

Fuente: Elaboración propia usando la base Casen 2009. 


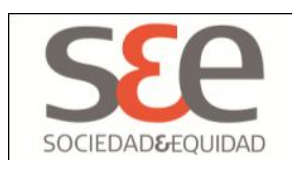

Sin embargo, Chile sigue evidenciando profundas brechas de distribución de ingresos y oportunidades, con un índice de Gini que permanece casi sin variaciones en los últimos 20 años, en valores de 0,57 a 0,55 (serie Casen 1990-2009). Simultáneamente a esta estabilidad de la desigualdad socioeconómica interna, los estudios longitudinales (FSP, MIDEPLAN, OSUAU, 2007) han evidenciado un circuito de la pobreza, en el que un segmento importante de la población $(27,4 \%)$ cae por debajo de la línea de pobreza, sale y puede recaer en el ciclo de una década 1996 2001-2006 (ver cuadro 1). Esta cifra de participación en el fenómeno de la pobreza puede extenderse aún más si se considera al conjunto de la población que en el transcurso de su ciclo vital ha vivenciado dicha situación. En esa misma lógica, estos estudios constatan que la pobreza dura (la población indigente en las tres mediciones) se encuentra extremadamente reducida, afectando solo un $0.25 \%$ de la población nacional. Por lo mismo, entender la pobreza actual implica asumir su dinamismo, y extender la observación de las características de este fenómeno a los grupos que temporalmente pueden encontrarse por sobre la línea de ingresos que define la pobreza, pero que han vivido o pueden vivir episodios de pobreza, frente a cualquier situación de riesgo que afecte a sus ingresos.

Cuadro 2. Dinámica de la Pobreza e indigencia en Chile 1996-2006.

\begin{tabular}{|c|c|c|c|c|}
\hline \multirow[b]{2}{*}{ SITUACIÓN DE POBREZA 1996 Y 2001} & \multicolumn{3}{|c|}{ SITUACIÓN DE POBREZA 2006} & \multirow[b]{2}{*}{ Total } \\
\hline & \begin{tabular}{|l} 
pobre \\
indigente
\end{tabular} & \begin{tabular}{|l|} 
pobre no \\
indigente
\end{tabular} & no pobre & \\
\hline pobre indigente en 1996 y 2001 & $0,25 \%$ & $0,31 \%$ & $0,44 \%$ & $1,00 \%$ \\
\hline pobre indigente en 1996 y pobre no indigente en 2001 & $0,16 \%$ & $0,83 \%$ & $1,00 \%$ & $1,98 \%$ \\
\hline pobre indigente en 1996 y no pobre en 2001 & $0,05 \%$ & $0,26 \%$ & $1,37 \%$ & $1,68 \%$ \\
\hline pobre no indigente en 1996 y pobre indigente en 2001 & $0,20 \%$ & $0,33 \%$ & $0,67 \%$ & $1,20 \%$ \\
\hline pobre no indigente en 1996 y 2001 & $0,32 \%$ & $0,94 \%$ & $3,35 \%$ & $4,61 \%$ \\
\hline pobre no indigente en 1996 y no pobre en 2001 & $0,15 \%$ & $0,96 \%$ & $8,55 \%$ & $9,65 \%$ \\
\hline no pobre en 1996 y pobre indigente en 2001 & $0,17 \%$ & $0,28 \%$ & $1,09 \%$ & $1,55 \%$ \\
\hline no pobre en 1996 y pobre no indigente en 2001 & $0,10 \%$ & $0,94 \%$ & $4,76 \%$ & $5,80 \%$ \\
\hline no pobre en 1996 y 2001 & $0,68 \%$ & $2,63 \%$ & $69,21 \%$ & $72,52 \%$ \\
\hline Total & $2,07 \%$ & $7,48 \%$ & $90,44 \%$ & $100,00 \%$ \\
\hline
\end{tabular}

Fuente: Elaboración propia usando la base de Panel Casen 1996-2001-2006 


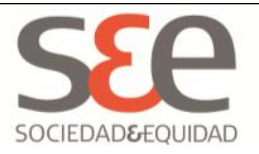

La dinámica de la pobreza a nivel de ingresos encuentra correlato en un conjunto de estrategias que van generado las personas para enfrentar esta situación socioeconómica, superar sus carencias y mejorar sus niveles de bienestar. Estas estrategias no son homogéneas, sino que responden a distintos marcos valóricos y disposiciones anímicas que han ido perfilando distintas expresiones de pobreza y una gran heterogeneidad del fenómeno.

Si bien es cierto que en el siglo XX y recientemente también, se han ensayado modelos comprensivos que definen la pobreza como culturas o subculturas (Lewis, 1959; Harrington, 1962; Moynihan, 1965) que han sido descartados por sus visiones deterministas, rígidas y con poco reconocimiento de la heterogeneidad interna (Monreal, 1996; citado en Espinoza, 2009: 12), en las últimas décadas se han intentado nuevas aproximaciones culturalistas que ponen en juego elementos contextuales de privación y marginalidad social, con determinadas configuraciones socioculturales de comprensión y acción frente a esta vivencia, que parecen interesantes de rescatar y resignificar. Más aún cuando estas configuraciones son reconocidas por sus propios actores y posibles de distinguir de otros, estableciendo juegos de identificación y pertenencia:

- Hay pobreza y pobreza. Igual no sé, la pobreza del hombre que vive en el estero es diferente del que vive en una media agüita igual tiene un techo.

- O el que tuvo mucho, y después, ahora no tiene nada.

- Porque igual uno pobre no puede ser si uno no tiene un plasma, no tiene un computador, sino que igual vale esto que uno tenga boca para hablar esto.

(Entrevista grupal Mujeres 30-45 años, Viña del Mar, Región de Valparaíso)

Esta heterogeneidad reconocida en la pobreza va más allá de identificar segmentos de población vulnerables. En los discursos se dejan entrever imágenes de pobreza por atraso tanto como de la pobreza de los modernos, descrita por Bengoa (1995); así como también imágenes de las llamadas "cultura de la pobreza" y de la "decencia" (Palacios y Martínez, 1996), las que son profundizadas en nuevas tipologías/arquetipos reconocidos por las propias personas que vivencia la pobreza y que se sintetizan en el cuadro 3. 


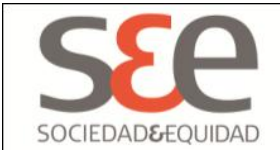

Cuadro 3. “Caracterización general de los perfiles de la pobreza detectadas en el estudio"

\begin{tabular}{|c|c|c|c|c|c|}
\hline \multirow{2}{*}{ Tipo } & \multirow{2}{*}{ arquetipo } & \multicolumn{4}{|c|}{ Características del perfil } \\
\hline & & $\begin{array}{l}\text { Inserción } \\
\text { educativa }\end{array}$ & $\begin{array}{l}\text { Inserción } \\
\text { laboral }\end{array}$ & Actitud & Valor \\
\hline \multirow{2}{*}{ Del esfuerzo } & $\begin{array}{l}\text { Luchador } \\
\text { resignado }\end{array}$ & $\begin{array}{l}\text { Educación } \\
\text { media } \\
\text { incompleta. }\end{array}$ & $\begin{array}{l}\text { Trabajador por } \\
\text { cuenta propia } \\
\text { o de inserción } \\
\text { laboral } \\
\text { precaria } \\
\text { inestable. }\end{array}$ & $\begin{array}{l}\text { Resignación } \\
\text { ante lo vivido }\end{array}$ & sacrificio \\
\hline & Emprendedor & $\begin{array}{l}\text { Educación } \\
\text { media } \\
\text { completa } \\
\text { nivelando } \\
\text { estudios. }\end{array}$ & $\begin{array}{l}\text { Trabajador } \\
\text { dependiente } \\
\text { con } \\
\text { estabilidad o } \\
\text { por } \\
\text { autoempleo. }\end{array}$ & $\begin{array}{l}\text { Proactividad y } \\
\text { Autocrítica }\end{array}$ & $\begin{array}{l}\text { esfuerzo } \\
\text { personal }\end{array}$ \\
\hline \multirow[b]{2}{*}{$\begin{array}{l}\text { De la } \\
\text { dependencia }\end{array}$} & Desganado & \multirow[b]{2}{*}{$\begin{array}{l}\text { Educación } \\
\text { media } \\
\text { incompleta. }\end{array}$} & Inactivo & Conformismo & \\
\hline & $\begin{array}{l}\text { Clientelista } \\
\text { asistencial }\end{array}$ & & $\begin{array}{l}\text { Desocupado o } \\
\text { con } \\
\text { inserciones } \\
\text { precarias }\end{array}$ & Oportunismo & \\
\hline \multirow[b]{2}{*}{ contra-cultural } & Delincuente & \multirow[b]{2}{*}{ Sin estudios } & & $\begin{array}{l}\text { Comodidad } \\
\text { (seguir el } \\
\text { camino fácil) }\end{array}$ & \multirow[t]{2}{*}{ sobrevivencia } \\
\hline & $\begin{array}{l}\text { Ex } \\
\text { delincuente } \\
\text { (papeles } \\
\text { manchados) }\end{array}$ & & $\begin{array}{l}\text { desempleados } \\
\text { sin } \\
\text { oportunidad }\end{array}$ & $\begin{array}{l}\text { Pesimista y sin } \\
\text { visión de } \\
\text { futuro }\end{array}$ & \\
\hline
\end{tabular}

Fuente: Fundación Superación Pobreza 2010:29 


\section{s\&e \\ SOCIEDADEEQUIDAD}

Estas conformaciones culturales de la pobreza van entretejiendo imaginarios construidos por los discursos mediáticos de la pobreza dura (el campamento) que refuerzan los medios de comunicación de masas, con las vivencias personales de enfrentamiento de la crisis, la carencia y la falta de espacios de participación socioeconómica. En estas distinciones, no todos los discursos están igualmente presentes. De hecho, el grupo de la pobreza esforzada es el más referido en las entrevistas y con mayor autoadscripción, seguido por el de la pobreza contracultural de quienes, habiendo cometido algún ilícito, tienen aspiración a reintegrarse socialmente. En ambos casos, sus discursos están cruzados por una representación social del emprendimiento y la disposición personal al sacrificio y trabajo como motor de movilidad social, y en ambos aflora una sensación de escaso reconocimiento y apoyo por parte de la política pública. Sobre estos discursos versa el presente análisis, sin desconocer el peso que tiene la pobreza dependiente en las representaciones sociales mencionadas y en la claridad de la relación que ésta establece con el Estado. Sin embargo, dado que estas referencias se estructuran bajo un discurso de observación y nunca de adscripción, se ha juzgado pertinente aislarlas en este análisis.

La pobreza del esfuerzo, caracterizada por una disposición y valoración del emprendimiento, refleja una nueva forma de concebir y enfrentar la pobreza que marca un fuerte desplazamiento desde las limitaciones del tener (imagen social de la carencia) hacia la insatisfacción definida por las restricciones en el hacer, que redundan en un malestar emocional resumido en la sensación de impotencia y de denegación de la libertad de elegir (Palomares, 2005). Esta comprensión de la pobreza que manifiestan quienes participan de su circuito, implica que el imaginario social ha transitado desde un concepto de pobreza absoluta y biológica de subsistencia -como la que inicialmente plantease Rowntree (1901, citado en Olavarría, 2005)-, hacia una pobreza relativa, dominada por una visión de capacidades, muy cercana a la conceptualización de Amathya Sen (1996) y a la de desarrollo humano (Max Neef, Elizalde y Hopenhayn, 1986).

La pobreza es impotencia porque [faltan] oportunidades de trabajo para las mujeres. Más para las mujeres, porque acá hay trabajo, pero son para hombres. Y cuando uno es jefe de hogar, no tiene un hombre que salga a trabajar, tiene que hacer el papel uno. Entonces, falta oportunidades de trabajo.

(Entrevista grupal, mujeres 30-45 años, Caldera, Región de Coquimbo)

- Me siento pobre cuando no tengo trabajo y soy joven, y tengo todas las ganes de trabajar y no encuentro trabajo; no hay posibilidades de trabajar.

- Para mí ser pobre es cuando uno tiene familia y toda la energía, todas las ganas de trabajar pero no hay. Uno se mueve por aquí y por allá, pero puras puertas cerradas. 


\section{sfe \\ SOCIEDADEEQUIDAD}

- Ahí uno se siente pobre, o sea, no pobre, sino que mal, ahí uno tiene que sacar fuerzas de flaqueza y decir la vida continúa y hay que seguir buscando.

(Entrevista grupal hombres 18-29 años, Tomé, Región del Biobío)

La no pobreza es tener lo suficiente para vivir, no para sobrevivir. Esta es la gran diferencia.

(Entrevista a dirigente sindical, Molina, región del Maule)

La no pobreza es poder optar a lo que tú quieres... no optar, como se dice, a las migajas.

(Entrevista grupal mujeres 18-29 años, Arica, Región de Arica y Parinacota)

\section{La pobreza equipada, una pobreza socialmente invisible}

Este nuevo perfil de pobreza, construido sobre un autoconcepto de esfuerzo, se percibe como poco reconocido por los otros grupos sociales y más aún las autoridades y operadores locales de la política social. Desde la propia reflexión y subjetividad de las personas que participan del circuito de la pobreza, esta invisibilización se explica por la escasa integración que existe del fenómeno de equipamiento de los hogares vulnerables y pobres, que se ha producido por la propia dinámica de la pobreza que permite la acumulación de bienes durables, en las etapas de mayor integración socioeconómica. Así entonces, surge el concepto de pobreza equipada o camuflada, no como una cultura o arquetipo, sino como una expresión de la experiencia que se sostiene con la estructura de oportunidades y/o sociedad no pobre. Este proceso se da aparejado a las necesidades psicológicas de integración simbólica y de dignificación de quienes, especialmente, participan de la cultura del esfuerzo, en cualquiera de sus variables, que busca a través de este equipamiento establecer una diferenciación respecto a la pobreza dependiente, y un posicionamiento social frente a sus pares.

La pobreza tiene mucha relación con la discriminación. La persona pobre se siente, de por sí, discriminada. Y cree y asume que con comprar un teléfono o comprar un televisor le va a subir el estatus y que así se va a sentir menos discriminado. Se va a sentir con más oportunidades. Entonces los enfoques son más diferentes. El pobre va a seguir siendo pobre y siempre va a tener sus necesidades. Pero la manera de afrontar la pobreza es otra. (Entrevista grupal Hombres 30-45 años, Cauquenes, Región del Maule) 


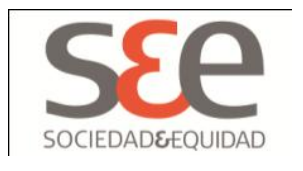

La pobreza siempre va a estar, pero me refiero a que con mejores medios, cosas así, porque antes la gente pobre no tenía ni tele, pero ahora tú vas y tienen tele, dvd, lavaplatos, cocina, de todo. $Y$ antes los campamentos no, po'. Los campamentos eran una loza, colchoneta y listo. Siempre va a existir la pobreza, pero de repente con mejores medios no más.

(Entrevista grupal mujeres 30-45 años, Antofagasta)

La masificación del equipamiento en la última década ha hecho perder capacidad de identificación de hogares en pobreza que tenía este indicador ${ }^{1}$, situación que se ve ratificada en las encuestas de caracterización socioeconómica. Tal como es posible observar en el cuadro 4, en el año 2003, el $61 \%$ de los hogares indigentes presentaban un equipamiento mínimo o nulo; cifra que ha bajado al $26,8 \%$ en el 2009. A su vez, los hogares con equipamiento alto aumentaron en más de 12 puntos porcentuales, pasando de 6,6\% en el 2003 al 19\% en el 2009. En los hogares pobres no indigentes se constata igual tránsito.

Cuadro 4. Disponibilidad de Bienes y Servicios Básicos de los Hogares*, según situación de pobreza

\begin{tabular}{|c|c|c|c|c|c|c|c|c|}
\hline & \multicolumn{6}{|c|}{ Situación de pobreza } & \multirow{2}{*}{\multicolumn{2}{|c|}{ Total }} \\
\hline & \multicolumn{2}{|c|}{ indigentes } & \multicolumn{2}{|c|}{$\begin{array}{|ll|}\text { Pobres } & \text { no } \\
\text { indigentes } & \end{array}$} & \multicolumn{2}{|c|}{ No pobres } & & \\
\hline & 2003 & 2009 & 2003 & 2009 & 2003 & 2009 & 2003 & 2009 \\
\hline $\begin{array}{l}\text { Sin } \\
\text { equipamiento }\end{array}$ & 16,7 & 3,3 & 8,4 & 1,5 & 3,5 & 1,0 & 4,6 & 1,1 \\
\hline $\begin{array}{lcc}1 & \text { a } & 2 \\
\text { artefactos } & \end{array}$ & 44,3 & 23,5 & 37,5 & 19,5 & 15,9 & 10,1 & 19,5 & 11,5 \\
\hline $\begin{array}{lcc}3 & a & 5 \\
\text { artefactos } & \end{array}$ & 32,4 & 54,2 & 48,3 & 61,3 & 48,5 & 45,4 & 47,9 & 47,2 \\
\hline 6 artefactos & 4,3 & 12,5 & 4,8 & 12,5 & 17,4 & 21,1 & 15,4 & 20,0 \\
\hline
\end{tabular}

\footnotetext{
${ }^{1}$ Se ha calculado el nivel de equipamiento de los hogares, siguiendo el índice de bienes perdurables que utiliza Cepal para el análisis de bienestar material. Sin embargo, para poder hacer comparable a través del tiempo la serie, se ha excluido el automóvil, ajustando el índice a la posesión de: alcantarillado, lavadora, refrigerador, calefón, teléfono fijo, computador y celular.
} 


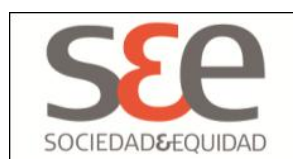

\begin{tabular}{|l|l|l|l|l|l|l|l|l|}
\hline $\begin{array}{l}\text { Todos los } \\
\text { artefactos }\end{array}$ & 2,4 & 6,5 & 1,0 & 5,2 & 14,7 & 22,3 & 12,6 & 20,2 \\
\hline Total & 100,0 & 100,0 & 100,0 & 100,0 & 100,0 & 100,0 & 100,0 & 100,0 \\
\hline
\end{tabular}

Fuente: Elaboración propia a partir de la base de datos Casen 2003 y 2009.

La volatilidad de los ingresos y su escasos rangos de diferenciación en los primeros tres deciles, así como este mayor equipamiento doméstico han dificultado el acercamiento cuantitativo y "objetivo" de la definición de la pobreza en la sociedad chilena. Esta pobreza no solo mayormente equipada pero también más educada y con menores tasas de mortalidad y morbilidad -todos indicadores con que tradicionalmente se abordaba su definición-, dificulta su identificación y contrasta fuertemente con los imaginarios sociales instalados sobre la cotidianeidad de la pobreza.

La política social ha tratado de avanzar en la incorporación de este nuevo perfil a través de la generación de un sistema de protección social, basado en un enfoque de vulnerabilidad más que en condiciones materiales de existencia, lo que se ha visto fuertemente reflejado en los instrumentos de focalización, particularmente en lo que respecta al reemplazo de la Ficha CAS-2 por la Ficha de Protección Social, en la que se eliminaron los módulos referidos a bienes perdurables de los hogares y condiciones materiales de la vivienda (Mideplan, 2006a, 2006b). Sin embargo, en las prácticas sociales de relacionamiento Estado/_sujeto en pobreza, que tienen lugar en los espacios locales, la comprensión de estos cambios en el perfil de la pobreza pareciera ir más lento. Esta disparidad entre cotidianeidad equipada y la autopercepción e imaginario social, está generando nuevos focos de exclusión social para quienes participan de la pobreza esforzada.

Yo jamás en mi vida salí a pedir, porque para mí, eso es como mendigar. Yo ahora igual cuando me fueron a encuestar a mi casa, igual mi puntaje es de más de 12 mil puntos, y yo fui a la municipalidad a reclamar por qué. Entonces la niña me dice - y eso que con una niña que nosotros nos conocimos años, la me fue me fue a encuestar-, y me dice: "no sé porque te sale tan alto tu puntaje". Y yo le digo: "entonces qué fuiste a ver a mi casa". ¿Qué es lo que le van a mirar a uno? Mi casa está empastada, tiene cerámica, y yo le digo por mí, porque yo lo hice, y lo hice sola. Yo empasté mi casa completa, pero porque yo quise salir adelante, yo no quise jamás vivir como vivieron mis padres en una ruca. Yo no quise darle eso a mis hijos tampoco. Entonces yo arreglé mi casa, terminé de pagar mi casa, yo la empasté, yo le puse cerámica, pero eso porque yo quise hacerlo, y por vivir cada día mejor. (Entrevista grupal mujeres 45 a 59 años, Alto Hospicio, Región de Tarapacá). 


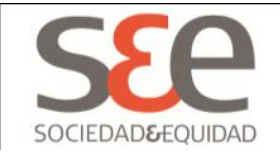

Cuando dicen, este país a salido adelante, es cierto. A lo mejor uno vivía en una rancha y ahora tendrá un techito mejor, pero dentro de eso pasan muchas cosas. Ven todo lo que está por fuera, lo bonito por fuera, pero lo que pasa adentro, porque uno mismo dice, usted podría ir a su municipalidad a pedir ayudar y la van ayudar pero resulta que antes de poner la cara en la municipalidad, mejor uno se queda ahí porque en la muni a uno siempre la ven por fuera: "chuta, usted no necesita y déjele a las personas que verdaderamente necesitan". Si uno no necesitara, no nadaría pidiendo que la ayudarán, porque si uno tiene de sobra para qué va a andar haciendo eso uno también, tiene vista para mirar y decir chuta ese también necesita. Pero a eso es a lo que yo voy, cuando dicen que Chile ha cambiado, sí, ha cambiado. A lo mejor estamos más grandes pero para el pobre no; el pobre siempre va a seguir siendo pobre y siempre le van a dar donde más le duele.

(Entrevista grupal mujeres 30-45 años, Padre Las Casas, Región de La Araucanía)

El avance material transgeneracional y el acelerado alejamiento de condiciones de precariedad y miseria reconocido por las personas en sus propias trayectorias vitales, es explicados por los propios entrevistados por una combinación de dos factores concurrentes: el esfuerzo propio y un rol más activo del Estado. Las facilidades para el acceso a la vivienda, la existencia de becas y apoyos estudiantiles son frecuentemente citadas en esta reducción de los índices y de la severidad de la pobreza en el país.

[...] el gobierno en realidad ayuda mucho, yo veo que ayudaba mucho a la gente, pero seguía en la misma pobreza porque no aprovechaban nada de lo que les daban.

(Entrevista grupal Mujeres 30-45 años, Padre Las Casas)

Yo pienso que la pobreza, de cierto modo, se ha superado un poco. Lo que se ha superado es la extrema pobreza, porque tenemos que tomar en cuenta que el gobierno ha hecho esfuerzos bastante grandes para superar la extrema pobreza: tenemos planes de vivienda, muchas personas pagan una ínfima cantidad de dinero -lo que no ocurría antes- y le entregan su casa y no pagan absolutamente nada; dan subsidios habitacionales donde se pueden adquirir viviendas de siete, ocho o nueve millones de pesos y también con un monto ínfimo de 200, 300, 400 mil pesos. Está el plan Puente, Chile Solidario... Entonces 


\section{S\&e}

hay programas de gobierno con los que, sobre todo aquí en Lota, se ha ido poco a poco superando la extrema pobreza, pero la pobreza hasta ahí se ha superado"

(Entrevista grupal hombres 60-75 años, Lota, región del Biobío)

Lo que llama la atención es que, pese al reconocimiento de un rol activo del Estado, la focalización de la política social lleva a que en la evaluación de la acción pública prime una sensación de desamparo y discriminación. Esta percepción está sustentada en una dimensión relacional de la pobreza, es decir, los vínculos que establece la población con la institucionalidad pública y viceversa, sobre la base de los prejuicios y visiones construidas que predominan respecto del Otro.

\section{Acción pública como discurso y como práctica de relacionamiento, vista desde la percepción del sujeto}

Las estrategias públicas de reducción de la pobreza ha ido evolucionando desde las prácticas de caridad, hacia una enmarcada en un enfoque de derechos, y que intenta, por un lado, asegurar condiciones básicas de dignidad, y por otro fomentar corresponsabilización de las personas con sus procesos de mejoramiento del bienestar. Sin embargo, esta transformación declarativa de los sentidos de la política social, convive con instrumentos -, particularmente subsidios- que otorgan un rol pasivo a las personas, reforzando un perfil de tono más bien asistencial que promocional en la política social actual. A ello se suma el distanciamiento entre lo que los diseños específicos de instrumentos definen en este campo y lo que ocurre en las prácticas de interacción entre funcionarios y sujetos en pobreza. Estas brechas de sentido ocurren tanto por la propia tradición e inercia que han generado los modelos subsidiarios de política social que dominara desde la década del ' 80 y que sólo se ha aminorado en los últimos gobiernos (Serrano y Raczynski, 2005), como por los estereotipos de pobreza que sostienen los operadores de la misma, propiciando que la política social siga operando bajo estrategias neoasistencialistas (Tenti, 1991), pese a declarar procesos promocionales.

Clasificación, caracterización y estereotipos: denegación social y deslocalización

La focalización de la política social en la atención de la extrema pobreza, a través del Chile Solidario y anteriormente en algunos grupos prioritarios, ha generado nuevos sistemas de clasificación de la población, que es percibida como estigmatizadora. De hecho, algunos estudios que han profundizado en el fenómeno de rechazo y abandono del programa Puente identifica este factor como uno de los elementos explicativos (Mideplan, 2005a: 35-36). 


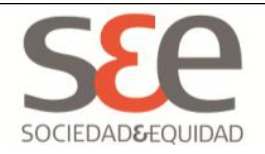

Fenómenos similares se registran en los discursos del presente estudio, con referencia a los efectos de la clasificación respecto a lo que implica ser FONASA tipo A, o a tener que "parecer" pobre renunciando a la dignidad personal, para que los funcionarios o la sociedad pueda reconocer su situación de desventaja.

Claro y con el asunto del [programa] Puente, van a la casa de la gente pobre y ven que están cochinos, y para ellos eso es pobreza y a ellos lo ayudan. Pero a nosotros, gente que trata de salir adelante, ya no son pobres, y eso te lo dicen en el área social cuando uno va arregladita.

(Entrevista grupal mujeres 46-59 años, Puerto Montt, Región de Los Lagos)

Te catalogan... ¿cómo te dijera yo? Un ejemplo: el Fonasa te cataloga por letra. Lo mismo ahí en el hospital. Si soy un " $A$ " te dejan pa'l último. Pero si soy un " $C$ ", ahí de los primeros, pase. Pero aunque se esté muriendo el "A", ahí tienes que esperar una hora, hora y media, dos horas.

(Entrevista grupal hombres 18 - 29 años, Copiapó, región de Atacama)

Hay gente que, ponte tú, existe en las municipalidades y en otras partes, que pasan la vida pagándole la boleta de la luz, y de repente hay alguien que tiene una casita bien, que se ha sacrificado, que se ha sacado la mugre comprándose un refrigerador, una estufa, y la tiene bien bonita, bien lavadita... No, para el gobierno esos no son pobres. Para el gobierno los pobres son la gente más cochina que ande. Esos son los pobres, ¿̇me entiende?

(Dirigenta Social Punta Arenas, Región de Magallanes)

El no reconocimiento de la pobreza del esfuerzo, a nivel de individuos y más aún a nivel de colectivos, se sustenta en imaginarios sociales que remiten a una pobreza por atraso (Bengoa, 1995). Es esta imagen contrasta con los discursos ciudadanizantes de la política social, toda vez que establece en la asociación pobreza / suciedad una visión paternalista y vertical con las personas en pobreza. Esta visión deniega, a la vez, la existencia de potencialidades y recursos que éstos tienen para encarar más activamente su situación.

Los sistemas de focalización de la política social generan, en ese sentido, un vínculo que refuerza la imagen de precariedad, y fomenta discursos y construcciones de autoconceptos desde la carencia, reforzando sensaciones de situación de marginalidad y frustración de esta población. 


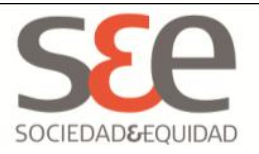

El perfil de pobreza esforzada establece una demanda social que llama a romper con la invisibilización de esta nueva pobreza, para reconocer, valorar e integrar los activos con los que cuentan las personas y los hogares en la acción pública. De esta forma se propiciarían vínculos más acordes a la disposición que se tiene a enfrentar las dificultades económicas y, se reconocería una actoría social, que favorecerá espacios de integración social por la vía de una progresiva autonomía. Esto surge desde el propio autoconcepto de este nuevo perfil de pobreza tiene de sí, y que requiere ser distinguido de la pobreza dependiente. Esta demanda de reconocimiento y dignificación, en definitiva, da cuenta del surgimiento de una conciencia de ciudadanía social que se siente trastocada o invertida en este tipo de relaciones basadas en una imagen avergonzante del otro (Satriano 2006: 7).

Tú tienes que buscar una solución de raíz: que te busquen un trabajo, que te ayuden en eso, [para] que tú puedas sobrevivir para ti y tu hijo, y no [estar] dependiendo de todos los años de marzo. A eso yo voy. No es tanto que la ayuden a una en dinero, sino en una oportunidad, porque una no está buscando que la mantengan toda la vida. Por eso no vas a estar esperando todos años ese mismo mes que te dieron veinte mil pesos o todos los años, marzo que te cubran tus gastos. Esa no es la idea.

(Entrevista grupal mujeres 18-29 años, Temuco, Región de La Araucanía)

Uno dice: necesitamos una oportunidad, un empujón, pero no que se lo regalen... Con el esfuerzo, con esfuerzo.

(Hombre 30-45 años, sector urbano Chiguayante, Región del Biobío)

Yo creo que al gobierno le corresponde preocuparse por nosotros, por poder entregarnos recursos, porque las necesidades de nosotros [las tenemos, pero] queremos trabajar, trabajar con la frente en alto. No andar pidiendo canastas familiares, no pedirle nada. Eso es lo que queremos.

(Dirigente pescadores artesanales Constitución, Región del Maule) 


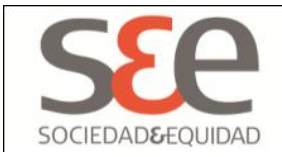

Distancia social y el gerenciamiento ilustrado de la política social

El desajuste de la política social al nuevo perfil de la pobreza, originado en estereotipos sobre esta población, marca el relacionamiento Estado / población pobre. Una de las causales argüidas en los discursos para explicar esta situación es el distanciamiento entre los policy makers y la población afectada por la pobreza. Esto permite que visiones deformadas de la realidad social sigan reproduciéndose y que el ejercicio de la acción pública lleve, por lo mismo, fuertes componentes de violencia simbólica al no reconocer la heterogeneidad del fenómeno y generar respuestas homogéneas para su superación.

El gobierno. Porque ellos no vienen a ver como la gente [vive]. Yo creo que ellos suponen no más, ya démosle esto. Porque ellos no vienen acá a terreno, a ver cómo la gente trabaja. (Entrevista grupal, mujeres 18-29 años, Vicuña, Región de Coquimbo)

A nosotros nadie nos escucha, el pueblo puede estar ahí pero nadie lo ve. Hay cosas del país hermosas, pero por qué no siempre se meten a las poblaciones, porque saben como es la realidad y la realidad que se está viviendo es la pobreza.

(Entrevista grupal, mujeres 18-29 años, El Bosque, Región Metropolitana)

El distanciamiento sentido se expresa también en la apreciación de poca empatía en la priorización del gasto público con la vivencia de la pobreza y en un estado anímico de mutua desconfianza. Las autoridades se encuentran cercanas a los grupos más favorecidos de la sociedad, por lo que tiende a preservar el status quo en vez de propiciar acciones que mejoren la distribución de ingreso y oportunidades.

El que tiene se ayuda solo a los que tienen, no más. A los pobres como que los dejan más a un lado. Se ayudan entre ricos. Los ricos se van a seguir haciendo más ricos... ...y van dejando a los pobres al lado.

(Entrevista grupal, hombres 30-49 años, Ovalle, Región de Coquimbo)

El gobierno [es responsable de la pobreza], porque ellos no ven más allá de ellos no más. No ven a la gente que está ahí, tan pobre, tan mal. Ellos se llenan ellos no más, porque ellos compran, imagínate, que gastan tanta plata en puras tonteras, que deberían gastarse 


\section{s\&e \\ SOCIEDADEEQUIDAD}

todo ese dinero en toda esa gente, para sacar adelante la gente que es tan pobre que está. A veces compran esas cuestiones de armas, de aviones, ¿para qué si se pueden gastar esa plata en sacar a esa gente que está tan mal?

(Entrevista grupal mujeres 18-29 años, Vicuña, Región de Coquimbo)

A qué voy, cuánta plata de toda esa que se despilfarra... Yo soy una de las reclamo todos los años para el año nuevo, cuántos millones se gastan las municipalidades en fuegos artificiales. ¿Por qué esos millones no lo destinan a la salud, no lo destinan para medicamentos, para camas en los hospitales? A mí no me interesa ver un fuego artificial, si yo veo que hay una persona grave que tiene donde hospitalizarse, valdría mucho más, se celebraría mejor un año nuevo. Entonces ahí es donde, sigue la pobreza.

(Entrevista grupal mujeres 60-75 años, Rancagua, Región de O’Higgins)

Ambas situaciones de distanciamiento social de los segmentos de pobreza y los grupos que toman decisiones sobre la acción estatal que debiese beneficiarlos muestra nuevamente un quiebre en los espacios de ciudadanía social que pueden ejercer quienes viven en pobreza. Esto representa una persistente exclusión, dada la escasa participación social y política que tienen estos sectores y que es percibida, incluso por las personas no organizadas que son parte del circuito de la pobreza, debido a la forma tecnificada y elitista de construir política social (Sojo, 2000).

\section{Cercanía ficticia y relación instrumental}

El distanciamiento social con la institucionalidad y el debilitamiento de los lazos sociales por desconfianza, se produce también por una sensación de uso instrumental de la pobreza por parte de autoridades, que establecen estrategias electorales a partir de una supuesta cercanía con quienes más sufren la desigualdad social. Sin embargo, la constatación reiterada de promesas incumplidas y de la recurrencia de estas prácticas, ha ido minando las posibilidades de establecer vínculos de capital social de escalera y societales que permitan mejorar su inclusión y participación social efectiva (Durston, 2003:160-161).

Es que mire, está bien lo que dice el vecino. Pero que hay un detalle. Como ahora, por ejemplo, vienen las elecciones. Prometen. Promesas, promesas. (...) Ahora, en estos días, se van a ver cosas que van a dar algo. Para asegurar el voto. Pero después el político se olvida de usted. (...) Entonces esos son los ejemplos malos que aquí uno no los entiende. 


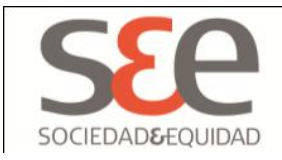

Los que mandan este país, los futuros que vienen de atrás a mandar este país, no van a servir para ponerlos como ejemplo para nuestros hijos o nuestros nietos. ¿Por qué? Porque resulta que la oportunidad se las dan ellos y no a los de abajo. El trabajador siempre va a ser explotado. Son 52 años en la espalda, que uno por lo menos algo sabe, ¿no cierto?

(Entrevista grupal hombres 46-59 años, Coquimbo)

Los políticos van cambiando, ellos echan a un ministro, echan a un diputado, y después viene otro, porque todos tienen que llenarse los bolsillos con las necesidades de los pobres. (Entrevista grupal mujeres 45-59 años, San Bernardo, Región Metropolitana)

La pobreza igual es especialización, por qué no la Presidenta mejora el estado de alguna gente que andan durmiendo en las calles, no le dan un hogar para vivir, un trabajo...Igual los diputados que hacen promesas y promesas, pasan los años y sigue lo mismo, y al final no hay ninguna solución. Sigue lo mismo: que van a subir los sueldos, vamos a mejorar la pobreza; llega el otro año y nunca hacen nada. Siempre siguen con las promesas de darle a los pobres, como uno.

(Entrevista grupal hombres 30-45 años, Punta Arenas, Región de Magallanes)

Política social de derechos y participación social, sin voz.

La representación que tienen las personas que participan del circuito de la pobreza sobre su relación con otros grupos sociales y autoridades, respecto a invisibilización de sus situaciones, el desconocimiento de la realidad concreta que se vive, y los escasos espacios de participación en las temáticas que son de pleno interés de quienes viven en vulnerabilidad y pobreza, refuerza la vivencia de la exclusión y de una pobreza impotente, incapaz de modificar su cotidianeidad, pese a su esfuerzo y su disposición. Como no se logra romper con la relación asimétrica que se establece con la institucionalidad pública y con las políticas sociales, les deniega la posibilidad de participar en sus procesos de superación. La falta de voz, o más bien la falta de escucha aparece como uno de los factores que define esta relación en sus diversos niveles, desde los espacios locales (municipio, consultorio) hasta los nacionales (parlamento y el gobierno). 


\section{s\&e \\ SOCIEDADEEQUIDAD}

De repente nos dejamos estar y no... La verdad es que no nos oyen, porque adonde somos pobres, no nos toman en cuenta.

(Entrevista grupal mujeres 18-29 años, San Fernando, Región de O’Higgins)

Si igual el gobierno, no toma en cuenta a nosotros realmente lo que somos, porque por una campaña que haiga, por elegir presidente, por elegir alcalde, recién ahora conocen a los pobres. Ahora todos son amigos con los alcaldes, amigos con los diputados, con todos. $Y$ después, llegado el momento, nadie anda tocando la puerta. Te falta alguna cosa, nada, en veces el pobre es el que elige al presidente $o$ al alcalde.

(Entrevista grupal hombres 30-45 años, Punta Arenas, Región de Magallanes)

Porque tenemos poca educación y no somos escuchados, los pobres no somos escuchados. Se dice que somos un país democrático, pero ¿dónde se respetan las minorías? Pero nosotros como minoría, no somos escuchados realmente.

(Entrevista grupal hombres 18-29 años, Copiapó, región de Atacama)

\section{Asistencia y promoción tensionando la política social}

Los vínculos que las personas en pobreza relatan en su relación con el Estado muestran importantes falencias en materia de integración social, pese a que hay una fuerte acción pública reconocida y valorada en la superación de la pobreza extrema. Este hecho se ha ido reforzando por las dificultades que encuentran los grupos u hogares que difieren de los estereotipos de la pobreza dura y autoabandonada. Si bien la política social ha ido mutando hacia la promoción y protección social, reconfigurando con ello la concepción de las personas en pobreza desde los sujetos carentes a sujetos con potencialidades y recursos propios que son posible de movilizar en pro de su propio bienestar, en la implementación se mantienen relaciones asimétricas y asistenciales, que no se ajustan a los requerimientos de dignificación y acompañamiento autonomizador que demanda la nueva pobreza.

El acompañamiento estatal mantiene focalizado sus esfuerzos en la pobreza menos "habilitada" en el decir de Irarrázaval (1995), y articulado desde la sospecha en la declaración que la propia gente hace de su situación de pobreza. Así se generan estímulos contradictorios en la población vulnerable, dado que quien mayor esfuerzo parece realizar, menor reconocimiento social y estatal recibe. Para muchos de los entrevistados, es la propia política social la que les define un rol pasivo y promueve la dependencia permanente del Estado, marcado por una acción de asistencia que cubre necesidades básicas más que por el otorgamiento de herramientas para emprender un 


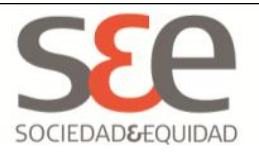

camino propio de superación. Pero es más, es este constante "regalo" desde el Estado el que va produciendo acostumbramiento y conformidad con la situación de dependencia, lo que se ve tanto en subsidios, apoyos a las viviendas, pero también en programas cuya finalidad debiese ser justamente promover la autonomía de ingresos, como son los Pro-empleo; o de integración social, como Puente de Chile Solidario.

Yo creo que el peor error del Gobierno y de los gobiernos, es que dicen, hay que apoyar a la pobreza. Pro empleo: ¿que van a hacer?, ya cualquier cosa. Entonces eso es fomentar más la pobreza. Tú no puedes tener pro empleo, que tengas unas viejas ahí, por ejemplo, en Coyhaique, que solo coloquen una malla con unas estaquitas y no le entreguen capacitación. Eso se llama fomentar más la pobreza, que ese círculo se transforme en vicioso, y hoy día tú tienes el claro ejemplo en Coyhaique, que hay ahí sindicatos de cesantes para postular al pro empleo, y en el pro empleo, ¿qué hacen aparte de, a veces, "barrer las calles"? Sacar la vuelta, o hacer estos trabajos que se ven ahí, colocar una malla con una estaquita. Pero eso no es sacar a la pobreza delante, porque esa pobreza aun queda más pobre, porque tú le pasas la plata para la comida, pero ese círculo vicioso es como un círculo vicioso de embrutecer al ser humano. Llega la temporada del pro empleo, yaaa... Se acabo la temporada del pro empleo, buuu... Eso es embrutecer al ser humano, eso es lo que peor que puede hacer el Gobierno. Un gobierno para sacar esto adelante, tiene que incursionar, ¿ंierto?, en cómo tú insertas al mundo laboral a esa persona. A través de este pro empleo, le generas una habilidad a través de la educación, yo prefiero en vez de que anden clavando esas estacas, las eduquen, porque van a tener una oportunidad de ir a insertarse

(Entrevista a dirigente sindical, Porvenir, Región de Magallanes)

Creo que los programas son muy buenos, yo lo veo muy buenos... Yo conozco, no mucho, pero el Programa Puente, se supone que es un puente para salir de la pobreza y avanzar un paso más. Siento que la gente pasó el puente y cuando ya lo cruzó, ya no le está gustando, porque ya no le están dando lo que le daban antes de cruzar el puente. $Y$ entonces, prefiere retroceder ese puente y ver de nuevo y gestionar si puede obtenerlo... Lo bueno que no va a poder obtener, creo el programa puente una sola vez lo puedes obtener.

(Entrevista grupal mujeres 18-29 años, Cartagena, Región de Valparaíso) 


\section{s\&e \\ SOCIEDADEEQUIDAD}

Por otra parte, la inversión en capital humano, que ha ido incrementando en la política social de mediano y largo plazo, se valora con un desestímulo en los instrumentos de focalización del sistema de protección social. Un ejemplo es la sensación de discriminación que las personas sienten al obtener altos puntajes en la Ficha de Protección Social por tener miembros del hogar con estudios medios completos, de la misma manera que antaño el haber invertido en el mejoramiento de la habitabilidad doméstica implicaba la no elegibilidad para los beneficios otorgados a través de la ficha CAS 2. Los nuevos instrumentos han aislado parcialmente a las personas de sus contextos de desarrollo y, aunque en teoría se aspira a poder integrar esta variable en la evaluación de la situación de las familias, esto aún no es técnicamente posible. Así entonces, en ambos casos, el esfuerzo y la inversión familiar se ve castigada por la misma política que acompaña a otros que no hacen mayores esfuerzos por superarse (pobreza dependiente).

Yo viví un caso así, que fue cuando yo estaba pidiendo para entrar en el programa Puente. Por el solo hecho de tener estudio, a uno lo discriminan más. ¿Por qué? Porque piensan que el nivel de superación es otro, porque piensan que lo intelectual te da más puntaje... no sé. Yo por decir un ejemplo: yo estudié el primer año, por el solo hecho de estar en la universidad a mí me daba otro puntaje... No, yo no terminé, yo dejé mi carrera ahí prácticamente todo, pero a mí me tomaban en cuenta como que yo era una profesional de repente, que yo ya tenía conocimiento. Yo me coloqué a reclamar una vez, para hablar con la jefa del desarrollo comunal. Me dijo: "usted debería estudiar mejor que todas, porque usted tiene un nivel intelectual más alto que las otras personas que son pobres". Una cosa así me dijo.

(Entrevista grupal mujeres 18-29 años, Arica, Región de Arica y Parinacota)

A mí me tenían que renovar la encuesta para la casa, y niña por Dios, no me la querían renovar, porque yo tenía una maquina industrial. Y le dije yo: esta máquina yo la tengo porque a mí me la dio el municipio, a mí me la dio la del proyecto puente, y me pude comprar mi máquina industrial, y pude trabajar y no me duró nada la cuestión. Así que olvídate." Entonces tuve que ir yo a la municipalidad, y dar con una lata a que me vengan a encuestar de nuevo, y que me bajara el puntaje porque mi casa es de madera. Mi pieza, tampoco es material sólido, pero hasta eso te miran, que no tienes dónde dormir, y tení que estar viviendo súper mal para que te tomen en cuenta.

(Entrevista grupal mujeres 18-29 años, El Bosque, Región Metropolitana) 


\section{s\&e \\ SOCIEDADEEQUIDAD}

Que tengamos una preocupación respetable de las autoridades, porque de repente no nos consideran mucho... No hay apoyo. Lo que pasa con la dicha Cas. Usted va a pedir la ficha Cas, y por el hecho que tiene cuarto medio, que tiene su tierra, su casita, no pasa a tener ningún apoyo de la municipalidad, porque consideran que usted tiene. Pero no se dan cuenta cómo se ha tenido eso y cómo vamos... cómo se está por abajo. Porque de repente, los que nos esforzamos para tener algo, es porque queremos vivir un poquito más digno, ¿no cree? Y que no se considere con lo otro como... para alimentarse de esto. Que nos den un subsidio... No, no lo hay. A los pobres pobres, eso sí tienen un subsidio.

(Entrevista dirigente pequeños agricultores, Vallenar, Región de Atacama)

\section{Conclusiones: Demandas sociales de dignificación y desafíos para la política social}

Las nuevas concepciones de pobreza que intentan abordar la complejidad del fenómeno, incorporando dimensiones subjetivas van a la par de la construcción de nuevos imaginarios sociales y autoconceptos de pobreza en la población que participa de este fenómeno. Junto a ello, va surgiendo una comprensión diferente de la relación Estado/ciudadanía, que ha ido demandando cambios en los enfoques con que se aborda la pobreza a través de la política social.

Un movimiento similar ha operado a nivel central respecto a la revisión conceptual y metodológica de la pobreza, en los organismos encargados de su monitoreo y del diseño de la acción pública que contribuya a su superación, pasando desde las descripciones centradas en el problema de carencias y disfuncionalidades sociales hacia una mirada comprensiva desde el marco de Derechos Humanos (MIDEPLAN, 2002). Estas transformaciones en la política social, sin embargo no han sido apropiadas profundamente por los operadores locales, manteniéndose visiones y acciones homogéneas sobre esta población. Sigue primando en el diseño y análisis de las políticas sociales una visión restringida de la pobreza, que centra su atención en el bienestar económico y particularmente en los ingresos disponibles por los hogares para desarrollar sus funcionamientos sociales (Larrañaga y Contreras, 2010: 60-61). Las mediciones que intentan establecer la magnitud y profundidad de la pobreza no han incorporado de manera clara las necesidades más subjetivas y de participación social que hoy definen ese perfil, ni tampoco han utilizado otras dimensiones de caracterización del bienestar que están incluidas en el mismo instrumental base (Encuesta Casen). Sólo recientemente se han empezado a indagar en nuestro país los alcances que tendría incorporar dimensiones faltantes de la pobreza, con nuevas estrategias de monitoreo y focalización que atiende a estos aspectos no reducibles a la dimensión ingreso y que hoy demandan con fuerza ser incorporados en el seguimiento del fenómeno (Alkire y Santos, 2010). 


\section{s\&e \\ SOCIEDADEEQUIDAD}

Los estudios cualitativos como los presentados en este artículo, ponen de relieve la necesidad de remirar estos procesos y buscar estrategias para deconstruir estereotipos asentados y favorecer una comprensión más amplia del fenómeno de la pobreza, que permita una actuación más pertinente por parte del Estado.

La política social chilena debe avanzar entonces hacia un mayor equilibrio en instrumentos que aseguren condiciones básicas de subsistencias, con aquellos que constituyen políticas de segunda generación, que apoyan el emprendimiento y la autonomía de las personas en pobreza y vulnerabilidad, con mecanismos pertinentes y por tiempo necesario para poder lograr una integración social lo suficientemente estable y sólida como para no decaer nuevamente a condiciones de pobreza. Para ello requiere repensar también los instrumentos de monitoreo y focalización que utiliza, de manera que puedan ser más sensibles a las dimensiones del estar y el hacer que la situación de pobreza obtura, y generar respuestas más acorde con este tipo de necesidades (Max Neaf, Elizande y Hoppenhayn, 1986). Además, esta nueva concepción obliga a repensar la acción pública en materia de superación de pobreza, desde una lógica sectorial, que atiende distintas dimensiones del desarrollo humano de manera parcializada, por una práctica sinérgica, de acción intersectorial, que en una estrategia conjunta aborde la complejidad de la vivencia de la pobreza, desde sus dimensiones más biológicas hasta el bienestar psicológico de los individuos.

Por otra parte, es necesario que policy makers y operadores locales de política social generen espacios críticos para analizar las externalidades que generan políticas subsidiarias que vuelven a centrar el problema de la pobreza en su dimensión de ingreso, y en la detección exclusiva de carencias. Esta autoobservación permitirá identificar y trabajar sobre las barreras sociales que impiden que los esfuerzos individuales, familiares y colectivos de quienes viven en pobreza y vulnerabilidad social, puedan generar niveles de bienestar suficientes que propicien la dignificación, el reconocimiento y la participación socioeconómica que demandan, incluyendo los efectos de invisibilización de recursos y activos disponibles y movilizables en dichas estrategias. Así también, la construcción de autoconcepto de pobreza es fruto de esta relación con la imagen social que persiste en otros. El estímulo que genera la política social y sus instrumentos de focalización, a definirse desde los problemas y la carencia, refuerza esta posición. Se requiere, entonces, iniciar una construcción una relación diferente, que intente rescatar sus recursos materiales, sociales y culturales, que los haga visible y que construya realidad de potencialidades, desde ese reconocimiento.

El desafío es grande, dado que persisten altos niveles de desconfianza en la relación Estado /población en pobreza, que han asentado un tono anímico de frustración y de constante discriminación, que tiende más bien a castigar la activación de recursos que a generar prácticas de apoyo que den la mencionada sustentabilidad a los procesos de superación que se propician desde los espacios microlocales. 
Rev. Sociedad\&Equidad № 1, Enero de 2011. Pp. 1-8

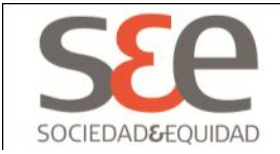

Sin embargo, la voz es clara en el sentido de que estamos frente actores sociales con grandes potencialidades, que reclaman un espacio de reconocimiento y que haga práctica cotidiana una relación Estado /sujeto, por sobre la de Estado/beneficiario. 


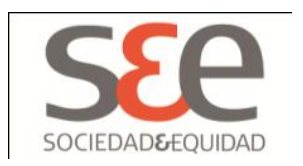

\section{Referencias}

Alkire, S. y Santos, M ${ }^{a}$. E. (2010) Acute Multidimensional Poverty: A New Index for Developing Countries. Working Paper N³8: 133pp, Oxford: OPHI.

Bengoa, J. (1995) La pobreza de los modernos. Temas Sociales 3, Marzo: Boletín del Programa de Pobreza y Políticas Sociales de SUR.

Comisión Económica para América Latina y el Caribe (2007) Panorama Social de América Latina. Santiago: CEPAL-Naciones Unidas.

Durston, J. (2003) Capital social: parte del problema, parte de la solución, su papel en la persistencia y superación de la pobreza en América Latina y el Caribe. En: Atria, R., Siles, M., Arriagada, I., Robison, L. J. y Whiteford, S. (comp.). Capital social y reducción de la pobreza en América Latina y el Caribe: en busca de un nuevo paradigma. Capitulo V, 147-202. Santiago: CEPAL-Naciones Unidas.

Espinoza, F. (2009. ¿Qué hay de nuevo en la discusión sobre la "nueva pobreza? En: FSP, Tesis País 2008. Piensa un país sin pobreza. Santiago: Fundación para la Superación de la pobreza.

Fundación Superación Pobreza, Ministerio de Planificación y Cooperación, Observatorio Social Universidad Alberto Hurtado (2007). La Encuesta Panel CASEN 1996, 2001, 2006: Primera Fase de Análisis. Santiago.

Extraído de http://www.osuah.cl/documentacion encuestapanelcasen/MINUTA Primera Fase Analisis Encu esta Panel CASEN 17oct07.pdf

Fundación Superación Pobreza (2010) Voces de la Pobreza. Santiago: Fundación Superación Pobreza.

Harrington, M. (1962) The other America. Poverty in the United States. New York: Touchstone.

Henríquez, H., Riquelme, V., y Galvez, T. (2006) Lejos del trabajo decente: El empleo desprotegido en Chile. Cuaderno de Investigación. №30: 180 pp, Santiago: Dirección del Trabajo.

Irarrazaval, I. (1995) Habilitación, pobreza y política social. Estudios Públicos N 59: 99-164 pp, Santiago: Centro de Estudios Públicos. 


\section{SEe}

Kaztman, R. y Filgueira, C. (1999) Marco Conceptual sobre activos, vulnerabilidad y estructura de oportunidades. Montevideo: CEPAL.

Larrañaga, O. y Contreras, D. (2010) Las nuevas políticas de protección social en Chile. Santiago: Uqbar Editores, PNUD, AECID.

Lewis, O. (1959) Antropología de la Pobreza. México: F.C.E.

Martínez, Javier y Margarita Palacios (1996) Informe de la Decencia. Santiago: Ediciones SUR.

Max Neef, M., Elizalde, A, y Hopenhayn, M. (1986) Desarrollo y Necesidades Humanas. En Max Neef, M. (ed.) Desarrollo a Escala Humana. Una opción para el futuro. Chile: CEPAUR.

Ministerio de Planificación y Cooperación (2001) Perspectiva de Derechos. Estrategia de Fortalecimiento de la Política Social para la década del 2000. Santiago: MIDEPLAN.

Ministerio de Planificación y Cooperación (2002) Síntesis de los principales enfoques métodos y estrategias para la superación de la pobreza. Santiago: MIDEPLAN.

Ministerio de Planificación y Cooperación (2005) Componentes Centrales de un Sistema de Protección Social sustentable: El nuevo escenario social en Chile. Santiago: MIDEPLAN.

Ministerio de Planificación y Cooperación (2005a) Estudio familias en situación de extrema pobreza que no han aceptado integrarse o han interrumpido su participación en el programa puente del sistema chile solidario. Cuadernillo $N^{\circ}$ 5. Santiago: Chile Solidario-MIDEPLAN.

Ministerio de Planificación y Cooperación (2006a) Documento de apoyo para el análisis del instrumento propuesto. Ficha Protección Social. (Comunicado de lanzamiento consulta ciudadana).

Ministerio de Planificación y Cooperación (2006b) Nueva Ficha de Protección Social. Un acceso más justo. Apuntes de Protección Social №2, Agosto. Santiago: Ministerio de Planificación.

Moser, C. (1998) The Asset Vulnerability Framework: Reassessing Urban Poverty Reduction Strategies. En World Development № 1. Vol. 26: 1-19. 


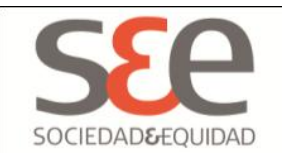

Moynihan, D. (1965) The negro family. The case for national action. USA: Office of Policy Planning and Research United States Department of Labor. También disponible en formato HTML en: < http://www.dol.gov/oasam/programs/history/webid-meynihan.htm>

Olavarría, M. (2005) Pobreza, crecimiento económico y políticas sociales. Santiago: Editorial Universitaria.

Palomares, J. (2005) Percepción de las causas de la pobreza, factores psicológicos asociados y percepción de la movilidad social. En: Székely (coord.), Desmitificación y nuevos mitos sobre la pobreza. 177-206. México: Miguel Angel Purrúa.

Satriano, C. (2006) Pobreza, políticas públicas y políticas sociales. Revista MAD N¹5, Septiembre. Departamento de Antropología. Universidad de Chile. Extraído de http://www.revistamad.uchile.cl/15/satriano.pdf

Sen, A. (1996) Capacidad y bienestar. En: Sen, A. y M. Nussbaum (comp.) Calidad de Vida. México: FCE.

Serrano, C. y Raczynski, D. (2005) Las políticas y estrategias de desarrollo social. Aportes de los años '90 y desafíos futuros, En: Patricio Meller (ed.) La Paradoja Aparente. Equidad y Eficiencia: Resolviendo el Dilema. 225-283. Santiago: Taurus.

Sojo, C. (2000) Dinámica Sociopolítica y Cultural de la exclusión social. En Gacitúa, E., Sojo, C. y Davis, S. (eds.) Exclusión social y reducción de la pobreza en América Latina y Caribe. 49 - 88. Washington: Banco Mundial.

Tenti, E. (1991). Pobreza y política social: más allá del neoasistencialismo. En: Isuani, E., Lo Vuolo, R. y Tenti, E., El Estado Benefactor. Un paradigma en crisis. Buenos Aires: Niño y Dávila. 


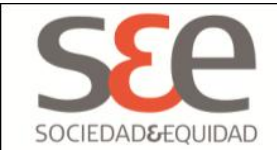

Cuadro 1. Estabilidad del empleo en asalariados, por decil de ingreso autónomo

\begin{tabular}{|r|r|r|r|r|r|r|r|r|r|r|r|}
\cline { 2 - 11 } \multicolumn{1}{c|}{} & \multicolumn{9}{|c|}{ Decil Autonomo Nacional } \\
\hline $\begin{array}{r}\text { Permanencia en el } \\
\text { empleo }\end{array}$ & I & II & III & IV & V & VI & VII & VIII & IX & X & Total \\
\hline Menos de año & 49,0 & 40,6 & 39,8 & 35,0 & 33,7 & 31,1 & 27,8 & 23,1 & 20,9 & 15,2 & 29,5 \\
\hline 1 a 3 años & 19,5 & 25,5 & 25,7 & 27,8 & 28,9 & 29,2 & 28,9 & 27,2 & 30,4 & 30,5 & 28,1 \\
\hline más de 3 años & 31,5 & 34,0 & 34,6 & 37,1 & 37,4 & 39,7 & 43,3 & 49,7 & 48,7 & 54,3 & 42,4 \\
\hline Total & 100,0 & 100,0 & 100,0 & 100,0 & 100,0 & 100,0 & 100,0 & 100,0 & 100,0 & 100,0 & 100,0 \\
\hline
\end{tabular}

Fuente: Elaboración propia usando la base Casen 2009.

Cuadro 2. Dinámica de la Pobreza e indigencia en Chile 1996-2006.

\begin{tabular}{|c|c|c|c|c|}
\hline \multirow[b]{2}{*}{ SITUACIÓN DE POBREZA 1996 Y 2001} & \multicolumn{3}{|c|}{ SITUACIÓN DE POBREZA 2006} & \multirow[b]{2}{*}{ Total } \\
\hline & $\begin{array}{r}\text { pobre } \\
\text { indigente }\end{array}$ & $\begin{array}{l}\text { pobre no } \\
\text { indigente }\end{array}$ & no pobre & \\
\hline pobre indigente en 1996 y 2001 & $0,25 \%$ & $0,31 \%$ & $0,44 \%$ & $1,00 \%$ \\
\hline pobre indigente en 1996 y pobre no indigente en 2001 & $0,16 \%$ & $0,83 \%$ & $1,00 \%$ & $1,98 \%$ \\
\hline pobre indigente en 1996 y no pobre en 2001 & $0,05 \%$ & $0,26 \%$ & $1,37 \%$ & $1,68 \%$ \\
\hline pobre no indigente en 1996 y pobre indigente en 2001 & $0,20 \%$ & $0,33 \%$ & $0,67 \%$ & $1,20 \%$ \\
\hline pobre no indigente en 1996 y 2001 & $0,32 \%$ & $0,94 \%$ & $3,35 \%$ & $4,61 \%$ \\
\hline pobre no indigente en 1996 y no pobre en 2001 & $0,15 \%$ & $0,96 \%$ & $8,55 \%$ & $9,65 \%$ \\
\hline no pobre en 1996 y pobre indigente en 2001 & $0,17 \%$ & $0,28 \%$ & $1,09 \%$ & $1,55 \%$ \\
\hline no pobre en 1996 y pobre no indigente en 2001 & $0,10 \%$ & $0,94 \%$ & $4,76 \%$ & $5,80 \%$ \\
\hline no pobre en 1996 y 2001 & $0,68 \%$ & $2,63 \%$ & $69,21 \%$ & $72,52 \%$ \\
\hline Total & $2,07 \%$ & $7,48 \%$ & $90,44 \%$ & $100,00 \%$ \\
\hline
\end{tabular}

Fuente: Elaboración propia usando la base de Panel Casen 1996-2001-2006 


\section{sfe \\ SOCIEDADEEQUIDAD}

Cuadro 3. "Caracterización general de los perfiles de la pobreza detectadas en el estudio"

\begin{tabular}{|c|c|c|c|c|c|}
\hline \multirow[b]{2}{*}{ Tipo } & \multirow{2}{*}{ arquetipo } & \multicolumn{4}{|c|}{ Características del perfil } \\
\hline & & $\begin{array}{l}\text { Inserción } \\
\text { educativa }\end{array}$ & $\begin{array}{l}\text { Inserción } \\
\text { laboral }\end{array}$ & Actitud & Valor \\
\hline \multirow{2}{*}{ Del esfuerzo } & $\begin{array}{l}\text { Luchador } \\
\text { resignado }\end{array}$ & $\begin{array}{l}\text { Educación } \\
\text { media } \\
\text { incompleta. }\end{array}$ & $\begin{array}{l}\text { Trabajador por } \\
\text { cuenta propia } \\
\text { o de inserción } \\
\text { laboral } \\
\text { precaria o } \\
\text { inestable. }\end{array}$ & $\begin{array}{l}\text { Resignación } \\
\text { ante lo vivido }\end{array}$ & sacrificio \\
\hline & Emprendedor & $\begin{array}{l}\text { Educación } \\
\text { media } \\
\text { completa o } \\
\text { nivelando } \\
\text { estudios. }\end{array}$ & $\begin{array}{l}\text { Trabajador } \\
\text { dependiente } \\
\text { con } \\
\text { estabilidad o } \\
\text { por } \\
\text { autoempleo. }\end{array}$ & $\begin{array}{l}\text { Proactividad y } \\
\text { Autocrítica }\end{array}$ & $\begin{array}{l}\text { esfuerzo } \\
\text { personal }\end{array}$ \\
\hline \multirow[b]{2}{*}{$\begin{array}{l}\text { De la } \\
\text { dependencia }\end{array}$} & Desganado & \multirow[b]{2}{*}{$\begin{array}{l}\text { Educación } \\
\text { media } \\
\text { incompleta. }\end{array}$} & Inactivo & Conformismo & \\
\hline & $\begin{array}{l}\text { Clientelista } \\
\text { asistencial }\end{array}$ & & $\begin{array}{l}\text { Desocupado o } \\
\text { con } \\
\text { inserciones } \\
\text { precarias }\end{array}$ & Oportunismo & \\
\hline \multirow[b]{2}{*}{ contra-cultural } & Delincuente & \multirow[b]{2}{*}{ Sin estudios } & & $\begin{array}{l}\text { Comodidad } \\
\text { (seguir el } \\
\text { camino fácil) }\end{array}$ & \multirow[t]{2}{*}{ sobrevivencia } \\
\hline & $\begin{array}{l}\text { Ex } \\
\text { delincuente } \\
\text { (papeles } \\
\text { manchados) }\end{array}$ & & $\begin{array}{l}\text { desempleados } \\
\text { sin } \\
\text { oportunidad }\end{array}$ & $\begin{array}{l}\text { Pesimista y sin } \\
\text { visión de } \\
\text { futuro }\end{array}$ & \\
\hline
\end{tabular}

Fuente: Fundación Superación Pobreza 2010:29 


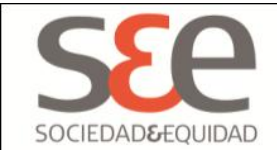

Cuadro 4. Disponibilidad de Bienes y Servicios Básicos de los Hogares*, según situación de pobreza

\begin{tabular}{|c|c|c|c|c|c|c|c|c|}
\hline & \multicolumn{6}{|c|}{ Situación de pobreza } & \multirow{2}{*}{\multicolumn{2}{|c|}{ Total }} \\
\hline & \multicolumn{2}{|c|}{ indigentes } & \multicolumn{2}{|c|}{\begin{tabular}{|l} 
Pobres no \\
indigentes
\end{tabular}} & \multicolumn{2}{|c|}{ No pobres } & & \\
\hline & 2003 & 2009 & 2003 & 2009 & 2003 & 2009 & 2003 & 2009 \\
\hline $\begin{array}{l}\text { Sin } \\
\text { equipamiento }\end{array}$ & 16,7 & 3,3 & 8,4 & 1,5 & 3,5 & 1,0 & 4,6 & 1,1 \\
\hline $\begin{array}{l}1 \text { a } 2 \\
\text { artefactos }\end{array}$ & 44,3 & 23,5 & 37,5 & 19,5 & 15,9 & 10,1 & 19,5 & 11,5 \\
\hline $\begin{array}{l}3 \text { a } 5 \\
\text { artefactos }\end{array}$ & 32,4 & 54,2 & 48,3 & 61,3 & 48,5 & 45,4 & 47,9 & 47,2 \\
\hline 6 artefactos & 4,3 & 12,5 & 4,8 & 12,5 & 17,4 & 21,1 & 15,4 & 20,0 \\
\hline $\begin{array}{l}\text { Todos los } \\
\text { artefactos }\end{array}$ & 2,4 & 6,5 & 1,0 & 5,2 & 14,7 & 22,3 & 12,6 & 20,2 \\
\hline Total & 100,0 & 100,0 & 100,0 & 100,0 & 100,0 & 100,0 & 100,0 & 100,0 \\
\hline
\end{tabular}

Fuente: Elaboración propia a partir de la base de datos Casen 2003 y 2009. 